\title{
Um Panorama Teórico do Campo de Públicas no Brasil: A agenda de estudos sobre Estado e Políticas Públicas
}

A theoretical overview of the Brazilian public field: the studies' agenda about state and public policies

\author{
Francymonni Yasmim Marques de Melo' \\ Jaedson Gomes dos Santos ${ }^{2}$
}

\begin{abstract}
RESUMO
O campo de públicas no Brasil é marcado pela inter, multi e transdiciplinariedade que enriquece e flexibiliza a área, mas que também pode gerar efeitos adversos, como a dificuldade de estabelecimento de uma identidade. Diante disso, este artigo baseouse no levantamento bibliográfico e sistematização de obras consolidadas na produção acadêmica nacional e internacional, objetivando estabelecer um panorama teórico geral sobre grandes temas basilares para estudos do campo de públicas, sobretudo o campo de Estado e politicas públicas, permitindo ao leitor de outras áreas, gestores e estudantes que pretendem ingressar, ou que já ingressaram em alguns dos diversos cursos do campo, um contato inicial com estes temas a partir de um único texto. A partir do levantamento da literatura, percebeu-se que os estudos de políticas públicas realizados no Brasil, ainda que possuam diferentes arsenais teóricos e focos empíricos, apresentam interseções conceituais que são introdutórias e fundamentais para a compreensão de temas mais profundos e complexos presentes na agenda do campo e, paralelamente, percebeu-se que há ainda carência de estudos nacionais em temas profundamente difundidos na literatura internacional..
\end{abstract}

Palavras-chave: Campo de Públicas. Políticas Públicas. Panorama teórico. Interdisciplinariedade. Multidisciplinariedade

\begin{abstract}
The public field in Brazil is characterized by inter, multi and trans-disciplinarity which enriches and loosens it, but it might also cause drawbacks, like the difficult of establishing an identity. So, this paper is based on bibliographic search and systemization of consolidated works in the national and international scholar production, aiming to set a general theoretical overview about fundamental topics for the study of public fields, mostly the field of State and public policies allowing readers from other sectors, administrators and students that intend to enter, or who have already entered any of the courses on the field, a first understanding of these topics from a single text. From literature research it was understood that public policy studies conducted in Brazil, albeit possessing different theoretical stockpiles and empirical focus, present conceptual intersections which are introductory and fundamental to the understanding of deeper and more complex issues on the field agenda, besides it was noted there is still a lack of national studies on issues remarkably widespread on international literature.
\end{abstract}

Keywords: public field. Public Policies. Theoretical overview. Interdisciplinarity. Multidisciplinarity.

\footnotetext{
${ }^{1}$ Mestranda no Programa de Pós-graduação em Estudos Urbanos e Regionais da Universidade Federal do Rio Grande do Norte (PPEUR/UFRN). E-mail: francymonni@gmail.com

2 Mestrando no Programa de Pós-Graduação em Gestão Pública e Cooperação Internacional da Universidade Federal da Praíba (PGPCI/UFPB). E-mail: jaedson_2029@hotmail.com.
} 


\section{Introdução}

O Campo de Públicas é uma área do conhecimento, inserida na grande área das ciências humanas, que agrega cursos como gestão pública, gestão de políticas públicas, ciências do Estado, gestão social, administração pública, entre outros (ALMEIDA et al, 2019). Devido a diversidade de cursos, o campo atraiu um grande quantitativo de estudantes em todo território nacional e aproximou gestores públicos do ambiente da universidade, seja como alunos dos cursos ou como parceiros em pesquisas e projetos de extensão que objetivam auxiliar a gestão na resolução dos problemas públicos ou na criação de políticas públicas setoriais.

Segundo as Diretrizes Curriculares Nacionais dos cursos de graduação em Administração Pública, os cursos do campo "compreendem o campo multidisciplinar de investigação e atuação profissional voltado ao Estado, ao Governo, à Administração Pública e Políticas Públicas, à Gestão Pública, à Gestão Social e à Gestão de Políticas Públicas" (RESOLUÇÃO Nº 1, DE 13 DE JANEIRO DE 2014, p.1).

Por causa da interdisciplinariedade, transdiciplinariedade e da diversidade dos cursos que compõem o campo, os estudos da área podem sofrer uma desagregação ainda mais forte que aquelas geradas pelos recortes conceituais e temáticos e isto pode resultar em dificuldade de fortalecimento de uma identidade do recente campo de públicas e é neste contexto que este trabalho se insere.

Cabe destacar que este artigo não tem como objetivo inserir novos elementos teóricos ou empíricos no debate de temas consolidados na agenda de estudos de políticas públicas no Brasil, ou ainda promover uma revisão teórica de todos os temas importantes do campo, mas sim estabelecer um panorama teórico geral sobre grandes temas basilares para diversos estudos do campo de públicas, sobretudo os temas relacionados a Estado e políticas públicas, permitindo assim, que leitores de outras áreas, estudantes que pretendem ingressar no campo (ou que acabaram de ingressar) e a gestores, um contato inicial a partir de um único texto com esses temas relevantes para a área.

À vista disso, em termos metodológicos, foi realizado um levantamento de algumas das principais literaturas sobre Estado e Políticas Públicas inseridas, principalmente, área da ciência política. Em seguida, foi realizado uma sistematização dos temas selecionados, adotando uma divisão entre os temas relacionados ao Estado e às políticas públicas. No que tange ao Estado, optamos por trazer a conceituação de Estado, bem como uma caracterização do Estado brasileiro.

Por outro lado, o segundo grupo de elementos conceituais trazidos agrega diversos temas sobre políticas públicas e, de modo mais específico, as discussões sobre o ciclo político-administrativo das políticas públicas, que é um elemento teórico importante para oferecer uma visão geral sobre todo o processo de políticas públicas e suas fases. Nessa parte de apresentação das fases do ciclo de políticas públicas, que são constituídas pela formação da agenda, formulação, implementação, monitoramento e avaliação, deuse uma atenção especial ao processo de implementação.

Posteriormente, apresentamos uma breve descrição dos principais modelos de análise de políticas públicas: os modelos pluralista, marxista, neoinstitucional, arenas de políticas públicas, múltiplos fluxos, equilíbrio pontuado e coalizão de defesa. Esses modelos, de modo geral, dividem-se em uma abordagem centrada na sociedade ou no Estado e são importantes ferramentas analíticas para explicar a produção de políticas públicas. Por fim, tem-se as considerações finais.

\section{2. $O$ conceito de Estado}

A ausência de cooperação na convivência dos seres humanos implica em desordem, confusão e um cenário no qual o homem depende unicamente de si para se proteger da ação de outros homens e a força (no sentido estrito de violência) é empregada para se atingir os objetivos da sobrevivência. A esta condição, denomina-se "estado de natureza". É nesta ideia que consiste a centralidade da perspectiva de Thomas 
Hobbes (2003) acerca dos contratos sociais, no qual idealiza-se o Estado (Leviatã) como o ordenamento das regras e do exercício de poder coercitivo para garantir que haja a cooperação entre os indivíduos.

Com o passar dos anos, diversos elementos foram sendo incluídos na temática do Estado, desde as visões a respeito da associação entre o desenvolvimento dos Estados modernos com a democracia, no qual podemos citar o papel da representação política como instrumento para fazer com que as vontade da coletividade, ainda que indiretamente e por sujeitos delegados, sejam consideradas na condução do Estado (BOBBIO, 1986), bem como a ideia do Estado enquanto Estado-nação, ou seja, a instituição de expressão e manutenção de uma comunidade política de características sociais, culturais e políticas inserida em um territorio (BRESSER-PEREIRA, 2017).

Por seu caráter extremamente amplo, torna-se impraticável discorrer sobre todas as dimensões das discussões sobre o Estado em artigos ou outras modalidades de trabalhos de curto alcance. Entretanto, para esse artigo, procuramos trazer ao debate uma dimensão singular e relativamente mais atual das discussões sobre o Estado e que consideramos ter relevantes implicações para o campo das políticas públicas, sendo esta a perspectiva da tensão entre o papel do Estado sob uma ótica das pretensões democráticas/representativas e o desenvolvimento do capitalismo, bem como de suas elites.

O Estado ainda pode ser definido, de acordo com Przeworski (1995), como abstrato, no qual os governos são as suas expressões, portanto, um governo pode ser do povo, do Estado ou do capital. No governo do povo, os governantes agem de acordo com os desejos e demandas dos governados. No governo do Estado, por outro lado, os governantes agem de acordo com os interesses estabelecidos dentro das instituições estatais e estas não precisam ser vinculadas aos desejos da sociedade. No governo do capital, os governantes agem de acordo com os interesses do mercado, do capital.

É importante distinguir Estado de Governo, principalmente para o estudo sobre políticas públicas. Desse modo, fazendo um paralelo entre Estado e governo, tem-se o Estado como uma entidade perene constituída por um conjunto de instituições permanentes (poder judiciário, exércitos, poder legislativo, tribunais, poder executivo, entre outros.) que viabilizam a ação governamental, enquanto o governo consiste em um conjunto de políticas e programa adotados por um grupo específico da sociedade e elegível a desempenhar tal função, abarcando os agentes políticos, os burocratas e organismos civis, dentro de um limite temporal estabelecido (HÖFLING, 2001).

Por sua função de regular as relações sociais e também de garantir as liberdades dos seus indíviduos (BRESSER-PEREIRA, 2017), quando inserido em contextos democráticos, os Estados modernos são fortemententes marcados por traços de liberalismo e também chamados de Estados liberais ou democracias liberais. Liberalismo, segundo Bobbio (1986), pode ser entendido por dois viéses, o econômico e o político. O liberalismo econômico, pela lógica do autor, tem relação com o papel do Estado em garantir as relações de mercado e o direito de propriedade, já o liberalismo político envolve os limites de intervenção do Estado nas individualidades (políticas e religiosas, por exemplo).

Devido ao expressivo crescimento do capitalismo como sistema hegemônico nos Estados ao redor do mundo, o liberalismo econômico tornou-se uma forte corrente de pesamento inclusive para as concepções do Estado, bem como de seus papéis na economia. Há nessa perspectiva liberal, o entendimento de que o mercado é uma entidade de mesmo patamar que o Estado e que o desenvolvimento dos Estados-nação passam pela não interferência do Estado na capacidade dos mercados de se auto-regularem e serem mais eficientes, para assim gerar riquezas para as suas sociedades (SMITH, 1983; FRIEDMAN, 1977). Entretanto, existem os contrapontos acerca da distribuição dessas riquezas. O pensamento de Karl Marx, revistado pela corrente neomarxista, parte de um pressuposto crítico de que o Estado é capitalisa e que então, por ser caputarado por grupos da elite econômica, tende a não considerar anseios da coletividade e atuar em prol da manutenção de estruturas que viabilizem que essas elites mantenham o seu status de acumulação de capital (POULANTZAS, 1980; 2001; OFFE, 1984). 
Nesse sentido, a ideologia é fator que também importa para compreender concepções de Estado, pois em alguma medida, as transformações políticas e econômicas dos Estados que ocorreram ao longo da história dos países estão associadas também a fatores ideológicos e teóricos. Destaca-se aqui, em termos de produção de políticas públicas, os Estados de bem estar social e neoliberal.

A visão do Estado de bem estar social decorre da preocupação sobre as assimetrias sociais geradas por um sistema no qual o capitalismo, sem a devida regulação, gere falhas de mercados e externalidades negativas, deixando cidadãos à margem da sociedade e desprovidos de direitos sociais básicos por não conseguirem acessar o mercado. É nessa problemática que se procura atribuir um novo sentido ao Estado, o de provedor de uma rede mínima de assistência para estes cidadãos vulneráveis, por meio de políticas sociais (MARSHALL, 1967; HÖFLING, 2001).

Como resultado da expansão dessas redes de proteção social e do consequente aumento do endividamento dos Estados, emergiu na corrente liberal a compreensão das políticas neoliberais, com a justificativa de otimização do gasto público e de ineficiência do Estado. Na perspectiva neoliberal, as políticas públicas estatais são indicadas como a causa das crises econômicas e fiscais dos Estados, e as de cunho regulatório, especialmente, são compreendidas como elementos de inviabilização da livre iniciativa, da concorrência e do crescimento econômico de maneira geral (HÖFLING, 2001).

\subsection{Organização e instituições do Estado Brasileiro}

O Estado brasileiro sofreu transformações. Durante o regime iniciado com o golpe de 1964, efetivou-se um modelo de Estado autoritário extremamente preocupado com o desenvolvimento econômico da Nação, mas sem considerar aspectos sociais e distante de pensar em justiça social. Com a abertura democrática e a promulgação da Constituição Federal de 1988, o Estado brasileiro assumiu um caráter mais democrático com a valorização da participação social, abertura de mecanismos públicos de controle, instituição de um modelo mais próximo da tipologia racional-legal de Weber, descentralizado e federalista. Entretanto, ainda permaneceram características patrimonialistas e clientelistas que são um desafio para a gestão pública e a sociedade brasileira até os dias atuais (NOGUEIRA, 1998; NUNES, 1997).

A retomada da democracia e o ambiente institucional estabelecido na Constituição Federal de 1988, possibilitaram a estruturação de um modelo de Estado federalista, com proteção social universal, a partir da provisão de diferentes tipos de serviços, bem como o aumento da descentralização que concedeu autonomia política aos estados e aos municípios brasileiros. $O$ termo federalismo refere-se a uma forma de organização que preza pelo sentimento de Nação (e a união que remete a este conceito), mas também entende que é necessário que cada unidade federativa (estados e municípios) possua autonomia. Destacase, porém, que federalismo e descentralização não são sinônimos e não estão completamente imbricados, pois diferentes compreensões do federalismo podem levar a arranjos com maior ou menor grau de descentralização (SOUZA, 2016; ARRETCHE, 2012).

No federalismo brasileiro, por exemplo, os governos subnacionais também se tornaram responsáveis pelas políticas públicas, porém com um diferencial: os estados e municípios receberam a competência para executar políticas públicas (policy making), mas não para decidir sobre como essa deve ser executada (policy decision-making) tema que cabe apenas ao governo federal. Assim, como efeito desse modelo, passou a ser demandado, do Governo Federal, uma maior capacidade de coordenação, exercida através da regulação nacional nas decisões sobre o desenho e o modo de operacionalização das políticas implementadas em escala subnacional e, por exemplo, do controle de recursos fiscais como instrumento de indução das prioridades. Já dos estados e municípios foram requeridas as capacidades necessárias para a implementação efetiva dessas políticas (ARRETCHE, 2012).

Inicialmente, ao se pensar em capacidades do Estado, era automático pensar no funcionamento da 
burocracia, partindo-se do pressuposto de que profissionais técnicos e competentes trabalhando em órgãos bem estruturados organizacionalmente e financeiramente criariam e implementariam, consequentemente, políticas públicas eficazes, eficientes e efetivas. Não desprezando esse aspecto, percebeu-se, nos estudos mais recentes, que outra dimensão, chamada de "político-relacional", também seria indispensável, pois está relacionada ao conceito de governança. Em outros termos, tem-se que a inserção de novos atores (sociedade civil e órgãos de controle) no processo de construção de políticas, assim como uma boa articulação entre eles, poderia tornar as políticas públicas mais efetivas (PIRES; GOMIDE, 2016, p.127).

Diante disso, entende-se que, devido à presença ou ausência de determinadas capacidades institucionais e as especificidades dos territórios, as políticas públicas nacionais geram resultados heterogêneos nos municípios em que são implementados e esses dois fatores explicam, portanto, os diferentes resultados após a implementação local das políticas nacionais.

\section{Políticas Públicas}

A partir das diversas noções de Estado, definir o conceito de políticas públicas não é uma tarefa fácil devido à sua abrangência e complexidade, porém, de acordo com Saravia (2006), em um texto introdutório sobre tema, elas podem ser definidas como "um fluxo de decisões públicas, orientado a manter o equilíbrio social ou a introduzir desequilíbrios destinados a modificar essa realidade" (SARAVIA, 2006, p.28). Ainda segundo o autor, apoiado em Thoenig (1985), as políticas públicas caracterizam-se por cinco elementos: medidas concretas, alocação de recursos, público-alvo definido, metas e objetivos claros e a inserção dessa política em outras ações dirigidas para resolver determinado problema social.

Dito isso, é possível se utilizar da clássica e sintética definição do Estado em ação (JOBERT e MULLER, 1987) para conceituar as políticas públicas e ao mesmo tempo abarcar todos esses elementos que as constituem. Considerando que Estado não é sinônimo de governo (HÖFLING, 2001), mas que o governo tem como função guiar o Estado com suas políticas governamentais, há portanto, um considerável foco no papel dos governos para a produção de políticas públicas, especialmente se pensarmos nos países com históricos de Estado de bem estar social. Por essa visão, a definição de Thomas Dye (1992) sobre "o que os governos fazem, porque fazem e que diferença isso faz", destaca o papel governamental na condução das políticas para a sociedade.

Entretanto, é importante dizer que a não-intervenção governamental também pode caracterizar uma política pública (DYE, 1992), pois de acordo com Lowi (1970), atores societais também podem produzir intervenções para problemas públicos, posto que uma política pública é, em geral, qualquer produto gerado por um tomador de decisão, seja em nível individual, a nível coletivo, a nível de governo ou a nível de organizações da sociedade. Isto posto, políticas públicas não podem ser reduzidas a uma visão estrita de políticas estatais (HÖFLING, 2001), e a entrega de políticas públicas por parte de organizações sociais (ou privadas) têm sido uma tendência emergente em contextos de crises fiscais dos Estados, em que as capacidades dos governos caem e aumenta o protagonismo dos atores sociais. Esse tipo de provisão de políticas é fortemente defendido academicamente pela corrente teórica da governança pública, ou pós-gerencialismo, e pode ser conceituado como governo indireto (SALAMON, 2002).

\subsection{Abordagem sequencial ou ciclo de políticas públicas}

$\mathrm{Na}$ tentativa de elucidar o processo de produção das políticas criou-se uma abordagem sequencial, ou clico de políticas públicas como é amplamente conhecido (LIMA; D'ASCENZI, 2013), que divide esse processo nas etapas de formação da agenda, formulação, implementação, monitoramento e avaliação. Essa abordagem é muito relevante teoricamente por oferecer um panorama simplificado, principalmente aos que 
estão tendo um contato inicial com as políticas públicas.

Contudo, apesar de ser um modelo relavente teoricamente, a ideia de ciclo de políticas públicas está se dissolvendo com o passar dos anos, pois esse modelo não é considerado uma abordagem analítica, devido a sua incapacidade de explicar fenômenos e a interseções entre as etapas que não são mais entendidas como estáticas, mas sim como dinâmicas, sobretudo quando observada a fase da implementação em que percebe-se que as políticas não são implementadas exatamente igual ao que foi planejado (LIMA; D'ASCENZI, 2013; HILL, 2005). Apesar dessas limitações, optou-se por usar esse modelo sequencial para explicar o processo de produção de políticas públicas, pois ele ainda é muito utilizado em textos introdutórios como um ponto de partida para uma compreensão mais ampla das políticas.

\subsubsection{Formação da agenda}

A primeira etapa se dá pela inserção de um determinado problema na agenda pública, isto é, quando um problema social é considerado pelos atores sociais e políticos como um problema relevante, sendo necessária, portanto, uma ação do Estado para resolvê-lo. Dessa forma, a agenda consiste em uma lista de problemas que receberão a atenção, existindo também aqueles problemas considerados prioritários dentro dessa lista maior (KINGDON, 2003).

Mas o que leva a escolha de um determinado conjunto de problemas e não outros? De acordo com Kingdon (2003, p.227), isso pode ser explicado pela forma como determinada "situação" passa a ser conhecida (indicadores, um evento-foco ou pelo feedback de uma política existente) e como esta "situação" é reconhecida como um problema (quando toca nos valores, comparação a realidades internacionais ou categorização).

Paralelamente, é necessário que exista, dentro do campo da politica, um cenário propício para a consideração desta situação como problema e ele entre na agenda, em que o momento da eleição é crucial, pois significa a abertura ou fechamento para determinados problemas, de acordo com o tipo de governo. Os atores políticos do alto escalão detém o poder de definição da agenda (KINGDON, 2003).

\subsubsection{Formulação de políticas públicas}

Para resolver o problema que agora é um problema público faz-se necessário o entendimento da complexidade do problema, bem como a consideração de alternativas para solucioná-lo e este processo é "inerentemente político" (CAPELLA, 2018, p.71). Nessa etapa, conforme Capella (2018) apoiada em Baumgartner e Jones (1993), os atores criam propostas de soluções para o problema e o empreendedor de políticas públicas é um ator importante na etapa da formulação, visto que faz a ponte entre o problema e a proposta de solução.

Chegando ao governo, as propostas de solução podem ser acatadas ou descartadas a partir da averiguação de qual alternativa é a mais viável social e economicamente, das características do governo e, princialmente, das ideias e visões de mundo dos atores políticos em disputa (KINGDON, 2003) e isto soma-se a fatores como o aprendizado de políticas que não deram certo, contexto, constragimentos ou incentivos instituicionais, entre outros, existindo portanto microdinâmicas e macroestruturas que explicam a escolha de alternativa $X$ e não de alternativa Y (CAPELLA, 2018). Após a escolha da melhor alternativa, a política pública é então desenhada com seus marcos jurídicos, objetivos, metas, resultados esperados e cálculo de recurso necessário.

\subsubsection{Implementação de políticas públicas}


Os primeiros estudos acerca da implementação de políticas públicas começaram a ser delineados nos Estados Unidos no final da década de 60 no contexto de luta da população negra por seus direitos civis e reinvindicações por políticas públicas de combate a pobreza, demanda que foi atendida pelo governo americano. Uma década mais tarde, começaram a surgir, de fato, os estudos sólidos acerca da implementação dessas políticas, objetivando entender se elas foram eficazes e quais os resultados (HONIG, 2006).

Esses estudos contribuíram para a quebra do paradigma da implementação como um processo natural após a formulação, mas, ao contrário, um processo complexo e global, marcado por uma ação conjunta entre diferentes atores, organizações e perspectivas, originado na formulação, re-formulado na execução e que só termina no impacto da política (PRESSMAN e WILDVASKY, 1973).

A implementação de políticas públicas pode ser pensada e pode acontecer de forma top-down ou bottomup. Na abordagem top-down, os implementadores são meros executores da política, devendo implementálas de forma exatamente igual a como ela foi formulada. Caso haja variações, essas são consideradas desvios de rota que podem afetar os resultados da política (NAJBERG; BARBOSA, 2006).

Assim, esse modelo pressupõe "um ambiente caracterizado por informação perfeita, recursos ilimitados, clareza de objetivos, linhas únicas de comando e autoridade e ainda legitimidade política e consenso quanto ao programa ou política" (NAJBERG; BARBOSA, 2006, p. 40). Esses itens são muito difíceis de existirem na prática, sobretudo o que refere-se ao consenso quanto a política pública em um país federalista como o Brasil, no qual os governos subnacionais podem constituir-se ou criar pontos de veto.

Por outro lado, a abordagem bottom-up defende o processo de implementação como um processo contínuo e não como apenas o que foi formulado sendo posto em prática. Nessa perspectiva, os implementadores também são tomadores de decisão que modificam, na ponta, o processo de formulação das políticas. Essa visão considera que os implementadores possuem autonomia e a usam para realizar modificações na política, corrigindo possíveis falhas na formulação ou como efeito das dificuldades de informação, de absorção dos reais objetivos. Ou seja, independente dos objetivos e das motivações, os implementadores realizam modificações na política (LOTTA, 2008; NAJBERG; BARBOSA, 2006).

Os estudos sobre a abordagem bottom-up abriram uma agenda de pesquisa sobre a atuação dos burocratas no processo de implementação de políticas públicas. Assim, começaram a surgir os primeiros estudos sobre a atuação dos burocratas de médio escalão e de nível de rua.

\subsubsection{Implementaçao sob a ótica da Burocracia de Nível de Rua}

Os estudos sobre burocracia de nível de rua surgiram nos Estados Unidos com o Lipsky (1980) ainda na década de 80 , mas só ganharam força no Brasil recentemente. Esses estudos de implementação focam nos profissionais de burocrata de nível de rua, isto é, aqueles que estão na ponta, lidando diriamente como os usuários das políticas. Para Lipsky (1980), é importante olhar o papel desses atores durante a implementação porque eles possuem discricionariedade na hora de executar as políticas.

A discricionariedade aqui pode ser entendida, de forma simplificada, como a liberdade de agir diante do que não está previsto na legislação ou no desenho institucional da política. As ações discricionárias desse burocrata podem ser motivadas por fatores como a forma como ele entende a política, as suas relações sociais com os usuários, as condições de trabalho, muitas vezes precárias e de escassez (LOTTA, 2012).

Autores adeptos de uma corrente top-down veem a discricionariedade desses burocratas como algo extremamente negativo e que gera efeitos perversos para as políticas como práticas clientelistas, entretanto, estudos recentes sobre a atuação dos burocratas têm achados importantes que revelam os efeitos positivos de determinados graus de autonomia desses burocratas apoiados, por exemplo, na teoria da representação 
democrática.

O distanciamento entre a formulação e a implementação, gerada pela combinação de escassez de recursos, ausência de determinadas capacidades estatais, favorece a discricionariedade dos burocratas que, na prática, precisam criar adaptações. Os burocratas de nível de rua são os implementadores de políticas públicas que estão em contato diário com os usuários, sofrendo pressões tanto dos profissionais quanto das pessoas que estão recebendo o serviço (LIPSKY, 1980). Esses profissionais "são responsáveis pela mediação das relações cotidianas entre o Estado e os cidadãos". Além disso, eles vivenciam, em grande medida, o mesmo contexto dos usuários tendo em vista que muitos residem no bairro e criam fortes vínculos com a comunidade (LOTTA, 2012, p. 25).

Além disso, Lotta (2012) defende que é importante estudar ações pontuais desses burocratas porque elas não refletem apenas um comportamento individual, mas representam aquele órgão estatal ao qual ele está vinculado. Os estudos desta autora sobre os agentes comunitários de saúde mostram os efeitos positivos da discricionariedade e da relação de pertencimento desse pessoal com a comunidade, inclusive fazendo a ponte entre a população e burocratas de médio escalão ou até mesmo facilitando o diálogo de uma população mais vulnerável com os médicos.

\subsubsection{Avaliação de políticas públicas}

A avaliação é a última fase do ciclo de políticas públicas. Conforme Trevisan e Van Bellen (2008, p.535), é dificil definir a avaliação de políticas públicas devido à multidisciplinariedade e a abrangência do campo, mas, de modo geral, os autores refere-se à "atribuir valor" a algo, neste caso a políticas públicas, baseado em critérios bem definidos. As primeiras avaliações surgiram na década de 60, assim como os estudos de implementação, nos Estados Unidos. Nessa fase, ainda segundo Trevisan e Van Bellen (2008), a preocupação está em saber se aquela política resolveu ou atenuou o problema que motivou a criação da política, se atendeu aos objetivos propostos.

As avaliações podem ser de diferentes tipos: ex ante, formativa ou ex post. As avaliações ex ante consistem em análises basicamente de viabilidade, considerando os custos econômicos e comparando com os benefícios, o impacto social. As formativas se assemelham muito ao próprio monitoramento, visto que acontecem durante a implementação da política, tentando fazer com que esse processo ocorra da melhor forma possível. Já as ex post visam mensurar a eficácia, eficiência e efetividade, isto é, se a política atendeu aos objetivos propostos, se atendeu aos objetivos propostos gastando o menor volume de recursos possível e, por fim, se atendeu aos objetivos com responsabilidade social (TREVISAN e VAN BELLEN, 2008). Cabe destacar que as avaliações não devem ser percebidas pelos agentes públicos como algo ameaçador ou amedrotador, mas como uma etapa de suma importância para o processo de aprendizado em políticas públicas.

\section{Análise de políticas públicas}

A análise de políticas públicas, assim como a avaliação, é um tema presente em diversos estudos brasileiros. A análise, diferentemente da avaliação, busca não só investigar se as políticas atingiram os objetivos propostos, se permitiu os melhores resultados com o menor gasto possível e se teve retorno social, ou seja, se foi eficaz, eficiente e efetiva, mas sim entender todo o processo de produção da política, focando em diferentes etapas ou atores, a depender do modelo de análise escolhido.

No Brasil e na literatura internacional, alguns dos modelos de análise de politicas mais consolidados são os modelos marxista, pluralista, neoinstitucional, dos múltiplos fluxos, equilíbrio pontuado e coalizão de defesa. Nesta seção recuperamos algumas das teorias apresentadas na seção anterior, mas de modo mais 
aprofundado.

\subsection{Racionalidade Limitada}

O modelo racional surgiu por volta de 1945 com Hebert Simon e objetivava explicar o processo de escolha de uma determinada política pública para resolver um problema social. Esse modelo afirmava que o processo de uma política pública é puramente racional, em que tem-se um objetivo claro e que, para atender a esse objetivo, é calculado racionalmente as alternativas e o custo-benefício de cada uma, sendo escolhida a melhor opção. Esse modelo foi durante criticado e, uma das principais críticas, consistia na impossibilidade de se mapear todas as alternativas existes para então escolher a melhor opção dentre elas.

Diante disso, foi criado, também por Hebert Simon (1955), o modelo da Racionalidade Limitada (bounded rationality) que consiste em um aperfeiçoamento do modelo racional a partir da incorporação de soluções para as criticas recebidas que afirma, com base em pressupostos teóricos da nova economia institucional, que os atores envolvidos em uma transação não são dotados da onisciência e que o que estes detêm é uma racionalidade limitada que não os permite contratualizar prevendo todos os eventos possíveis (WILLIAMSON, 1985), inclusive nas decisões tomadas para formular políticas, escolher determinados tipos de soluções ou quais problemas públicos devem ser priorizados pelo Estado.

\subsection{Pluralismo e Marxismo}

Os modelos de análise Marxista e Pluralista possuem como ponto comum o foco nos atores para explicar o processo das políticas públicas. No caso do modelo pluralista, o principal argumento é que os atores sociais têm muitos interesses e preferências e, quando organizados em ambientes como ONG's, partidos políticos, coletivos, formam grupos de pressão sobre os agentes políticos, aplicando-se, portanto, apenas a análise em governos democráticos (MENY e THOENIG, 1992). Considerando que em uma sociedade existem diferentes demandas e diferentes grupos de interesse, os mais organizados conseguem exercer mais pressão sobre o Estado que é um agente neutro nessse processo. Assim, as políticas, nesse modelo, refletem as características da sociedade (CARNOY, 1986; MARQUES,1997).

Se no modelo pluralista todos os grupos têm a mesma chance de conseguir que o Estado atenda as suas demandas e o Estado é um agente neutro, no modelo marxista o Estado age em favor da classe social dominante: a elite, portanto as políticas criadas não podem ir contra o interesse dessa classe. Esse modelo surgiu por volta do século XX e apresenta uma explicação macro para as políticas públicas (MARQUES,1997).

\subsection{Neoinstitucional}

O modelo institucional surgiu objetivando mudar o foco existente nos modelos anteriores (da escolha racional, marxista e pluralista) dos indivíduos para o Estado, tendo em vista o argumento que o Estado não é um agente neutro, mas é um agente desse processo através de suas instituições (IMMERGUT, 1996; HALL e TAYLOR, 2003). Dentro desse debate, as instituições podem ser entendidas como as regras do jogo na sociedade, da mesma maneira que consistem nos constrangimentos humanamente idealizados para moldar as interações entre os humanos. De maneira complementar, as instituições promovem os incentivos para as trocas sociais nos campos político, econômico e social (NORTH, 1990). Ainda, por esse olhar, têm como papel reduzir as incertezas, ao passo que promovem uma estrutura, por vezes eficiente, de interações sociais de longa duração que orientam e moldam comportamentos para previsíveis e desejáveis.

Seguindo a lógica de North (1990), as instituições podem ser vistas como formais, tais como as leis e 
regimentos, ou, como informais, como por exemplo, as convenções e os códigos de comportamento. Apesar de separadas, em termos analíticos, as instituições também podem ser formais e informais ao mesmo tempo, uma vez que as regras informais (não previstas em texto) podem complementar as regras formais, ou mesmo, as regras formais podem sofrer influência dos constrangimentos informais culturalmente instituídos.

Este modelo ganhou força sob o slogan que as instituições importam (IMMERGUT, 1996). Em termos empíricos, por exemplo, o subsídio que o governo federal a estados e municípios para a implementação de determinadas políticas é um incentivo a implementação. Assim como, quando um município opta por não aderir a uma política ou não segue os princípios norteadores do desenho institucional, ele para de receber o recurso isso é um constrangimento a não adesão (MARQUES, 1997).

O modelo neoinstitucional de análise de políticas públicas é muito utilizado para explicar políticas públicas brasileiras, sobretudo em estudos que focam em explicar o desenho e os arranjos estabelecidos nas políticas públicas a partir de um olhar sobre a Constituição Federal de 1988.

\subsection{Arenas de Políticas Públicas}

É sob a noção de que as políticas públicas (policy) determinam a política (politic) que Theodore Lowi (1964; 1970 ; 1972) deu significativa contribuição para o campo da análise de políticas públicas ao desenvolver tipologias de classicação para as diferentes políticas públicas que podem ser produzidas pelo Estado. Para o autor, determinadas políticas públicas geram diferentes posicionamentos entre os grupos afetados pela intervenção do Estado, sejam posicionamentos favoráveis à intervenção ou contrários à intervenção. Dessa maneira, Lowi argumenta que as políticas públicas se configuram em: 1) distributivas 2) redistributivas 3 ) constitutivas e 4) regulatórias. Assim, cada tipo de política pública vai gerar uma arena específica de relação política entre o governo e os grupos envolvidos, com apoio, oposição, ou mesmo ambos.

No Caso das políticas distributivas, são aquelas que atendem clientelas específicas e são custeadas pela coletividade, ou seja, o conjunto de cidadãos que contribui com o Estado por meio dos impostos e taxas. Como exemplos desse tipo de política pública, podemos tomar os serviços públicos de saúde e educação, as políticas de seguridade e assistência social, etc. É um tipo de política no qual se desconsidera, em grande medida, a limitação dos recursos e seus impactos acabam sendo mais no nível dos indíviduos, do que no nível univeral, uma vez que são direcionadas a grupos específicos. Ainda assim, é uma tipo com baixo nível de divergência e considerável grau de barganha entre os grupos políticos, por não apresentar claramente os desfavorecidos.

As políticas redistributivas por sua vez, são políticas também direcionadas a clientelas específicas, mas que ao invés de serem custeadas pela coletividade, são produzidas mediante recursos oriundos de grupos específicos da sociedade. Por exemplo, políticas de reforma agrária e de redistribuição de recursos entre entes federados. Esse tipo de política é marcado por um alto grau de conflitos na arena política, devido ao sue caráter de imposição de perdas concretas para um grupo e ganhos incertos para os beneficiários e principalmente para a coletividade.

Já as políticas regualtórias, são fortemente marcadas por um viés coercitivo e são voltadas para o estabelecimento de regras de convivência entre os cidadãos nas sociedades, tanto para restringir, quanto para direcionar os comportamentos, as atividades e as relações dos cidadãos e entre os cidadãos. Podem ser direcionadas para o indíviduo, organizações ou a sociedade em geral. São exemplos desse tipo de políticas os códigos de trânsito e as leis de veiculaçaõ de propaganda. É também uma política cuja arena produz alto grau de conflitos no âmbito político, mas com maiores possibilidades de negociação, por evidenciar quem perde e quem ganha com determinada regulação mas sem redistribuir recursos para alocar. 
Por fim, as políticas constitutivas são direcionadas para os ordenamentos formais que constituem o Estado, ou seja, as normas que vão definir as regras do jogo para a estrutura do Estado (poderes), para os governos, para os atores políticos e também para a tomada de decisão das políticas distributivas, redistributivas e regulatórias. Os principais exemplos desse tipo de política remetem às constituições federais, as legislações eleitorais, etc. Além disso, tem na sua arena uma configuração menos conflituosa, com padrões de transação mais voltados para a negociação política e a cooptaçaõ de grupos de apoio.

\subsection{Múltiplos Fluxos}

O modelo analítico dos múltiplos fluxos surgiu com o Kingdon (2003), apoiado no modelo da Lata de Lixo de Cohen, March e Olsen (1972), a partir dos seus estudos sobre como um problema entra na agenda pública e como é o processo de tomada de decisão, em que o foco está no papel das ideias. Para ele, isto pode ser explicado a partir de três fluxos: do problema, das políticas públicas e da política.

O primeiro fluxo, do problema, refere-se ao momento em que uma situação é reconhecida como um problema, como explicado na subseção sobre agenda. Posteriormente, no segundo fluxo, entram em disputa alternativas para solucionar esse problema que estão relacionadas a valores, visões de mundo em oposição a uma pura racionalidade. Nesse momento, grupos de especialistas, empreendedores políticos, comunidades de políticas, se articulam em defesa da alternativa que é a melhor solução para o problema de acordo com as suas visões. Por último, tem-se o fluxo da política que consiste no contexto político propício para a efetivação dessa política pública Esses fluxos são independentes, porém, quando se encontram abrem uma janela de oportunidade para a política pública (KINGDON, 2003; GOTTEMS et al, 2013; CAPELLA, 2007).

\subsection{Equilibrio Pontuado}

O modelo do equilíbrio pontuado, é mais complexo do que o modelo neoinstitucional. Por ser uma teoria mais recente, incorporou contribuições e criticas tecidas aos outros modelos, por isso, pode-se dizer que o modelo do equilíbrio pontuado bebeu de elementos da escolha racional, do pluralismo, do neoinstitucionalismo e, sobretudo, do modelo dos múltiplos fluxos do Kingdon. Esse modelo visa explicar a permanência e a mudança na agenda governamental, olhando o papel das instituições, dos atores e das ideias nesse processo. Para atender a esse fim, estudos que usam o equilíbrio pontuado (ou interrompido) para analisar políticas públicas necessitam de um recorte temporal extenso (CAPELLA e BRASIL, 2015).

De modo geral, esse modelo considera que existem períodos que temas entram na agenda e se tornam alvo da atenção pública. Esses temas podem sair posteriormente da agenda e demorar anos para voltar ou nunca mais voltar. Cria-se uma imagem positiva acerca da política, gerando um monopólio. Um conceito fundamental para esse modelo é o de comunidades de políticas públicasque refere-se aos especialistas de determinada área de política pública (CAPELLA e BRASIL, 2015).

\subsection{Coalizões de Defesa}

O modelo de coalizões de defesa (advocacy coalition) foi idealizado por Sabatier (1988) e aprimorado por Sabatier e Jenkins-Smith (1993). Os modelos dos múltiplos fluxos, equilíbio pontuado e coalizão de defesa possuem como ponto comum o foco nas ideias, crenças e valores. No modelo de coalizões de defesa, em específico, procura-se entender a influência na tomada de decisão pelo prisma dos atores coletivos, ou seja, como grupos de interesse ou mesmo arranjos entre diferentes organizações competem entre si para incluir suas preferências nas políticas governamentais. 
Segundo Sabatier (1988), as coalizões resultam da cooperação entre diversos atores envolvidos de alguma maneira com o processo de produção de uma política pública, sejam estes atores políticos, burocratas, acadêmicos, ativistas, influenciadores de opinião, etc. A coalizão se mantém coesa devido às conviç̧ões e às ideias desses atores se manterem convergentes, ainda que haja alguma discordância sobre elementos menos relevantes.

Assim, o modelo de coalizão de defesa é um importante instrumento analítico para compreender não só como se dão os grupos que influenciam as políticas políticas públicas, mas também como estas mudam, muito em função da compreensão de que as políticas são formadas por subsistemas gerados por coalizões com relativa distinção de perspectivas, valores, ideias e formas de influenciar, e que esses subsistemas também estão associados a fatores externos que podem ser determinantes para a mudança, como nos casos de crises econômicas e políticas, da reorganização no campo político partidário, ou mesmo os impactos de políticas públicas de outros subsistemas (SABATIER e JENKINS-SMITH, 1993). Além dessa face, o modelo de coalizão de defesas também indica que as mudanças podem decorrer do processo de aprendizagem das coalizões que resultam do seu envolvimento com a política (policy-oriented learning), e que assim, podem trazer para a coalizão ressignificações das suas perspectivas, ideias, valores e crenças.

\section{Considerações Finais}

Considerando a apresentação desses comentários acerca de temas chaves para o estudo de políticas públicas no Brasil, espera-se que o leitor tenha o desejo de realizar mais leituras e aprofundar os seus conhecimentos acerca de cada tema, pois acreditamos que a aplicação desses conceitos e teorias a diferentes objetos de estudo, podem contribuir para novas discussões sobre políticas públicas, não apenas no âmbito acadêmico, mas também da gestão governamental.

Contudo, ressaltamos a dificuldade, dada a inter e transdisciplinariedade inerentres ao campo, de sistematizar discurssões teóricas das diferentes áreas (administração, sociologia, economia, etc.) que compõem o campo de públicas e, por essa razão, optamos por focar basicamente nas contribuições da área da ciência política para este campo do conhecimento. Destacamos também que, durante o levantamento bibliográfico, constatou-se a necessidade de mais estudos nacionais focados em temas relevantes para o campo de públicas que são amplamente difundidos internacionalmente e ainda subexplorados no cenário nacional.

Portanto, como agenda de pesquisa, evidencia-se a necessidade de produção de mais ensaios teóricos focando em temas basilares para o campo de pública sob a ótica das diferentes áreas que o compõe, assim como de temas que necessitam de aprofundamento no Brasil, como a burocracia de médio escalão, difusão de políticas públicas, e coprodução de políticas públicas, por exemplo, objetivando popularizar nacionalmente discussões amplamente difundidas no cenário internacional, ao passo que também se produzam mais reflexões teóricas sobre as especificidades de politicas públicas do contexto brasileiro.

\section{Referências}

ALMEIDA, Lindijane de Souza Bento; RODRIGUES, Maria Isabel Araújo; SILVEIRA, Raquel Maria da Costa. ENSINO NO CAMPO DE PÚBLICAS: o caso dos cursos da Universidade Federal do Rio Grande do Norte (UFRN) e da Escola de Governo da Fundação João Pinheiro (EG/FJP). NAU Social, v. 9, n. 17, 2018.

ARRETCHE, Marta. Democracia, federalismo e centralização no Brasil. Rio de Janeiro: Editora Fiocruz, 2012. 
BOBBIO, Norberto; NOGUEIRA, Marco Aurélio. O futuro da democracia: uma defesa das regras do jogo. Rio de Janeiro: Paz e Terra, 1986.

BRESSER-PEREIRA, Luiz Carlos. Estado, Estado-Nação e Formas de Intermediação Política. Lua Nova, São Paulo, v. 0, n. 100, p.155-185, jan. 2017.

CAPELLA, Ana Cláudia Niedhardt. Formulação de Políticas Públicas. Brasília: Enap, 2018.

CAPELLA, Ana Cláudia Niedhardt. Perspectivas teóricas sobre o processo de formulação de políticas públicas. In: HOCHMAN, G. et al. (Org.). Políticas públicas no Brasil. Rio de Janeiro: Fiocruz, 2007. p. 87121.

CAPELLA, Ana Cláudia Niedhardt; BRASIL, Felipe Gonçalves. Análise de políticas públicas: uma revisão da literatura sobre o papel dos subsistemas, comunidades e redes. Novos Estudos-CEBRAP, n. 101, p. 5776, 2015.

CARNOY, Martin. Estado e teoria política. Campinas. Papirus, 1986.

DYE, Thomas R.; DYE, Thomas R. Understanding public policy. Englewood Cliffs, NJ: Prentice Hall, 1992.

FRIEDMAN, Milton. Capitalismo e Liberdade. São Paulo. Arte Nova,1977.

HALL, Peter A.; TAYLOR, Rosemary CR. The three versions of neo-institutionalism. Lua Nova, n. 58, p. 193223, 2003.

HOBBES, Thomas. Leviatã. Martins Fontes, 2003.

HÖFLING, E. de M. Estado e políticas (públicas) sociais. Cadernos CEDES, Campinas, v.21, oㅡ 55, nov. 2001.

HONIG, Meredith I. New directions in education policy implementation. Suny Press, 2006.

IMMERGUT, Ellen M. As regras do jogo: a lógica da política de saúde na França, na Suíça e na Suécia. Revista Brasileira de Ciências Sociais, São Paulo, n. 30, p. 139-165, 1996.

LIPSKY, Michael. Street-Level Bureaucracy: Dilemmas of the individual in public services. New York: Russell 
Sage Foundation, 1980.

LOTTA, Gabriela Spanghero. O papel das burocracias do nível da rua na implementação de políticas públicas: entre o controle e a discricionariedade. Implementação de políticas públicas: teoria e prática. Belo Horizonte: PUC Minas, p. 20-49, 2012.

LOWI, Theodore J. American Business, Public Policy, Case Studies, and Political Theory. World Politics, vol. 16, pp. 677-715. 1964.

LOWI, Theodore J. Decision Making vs. Policy Making: Toward an Antidote for Technocracy. Public Administration Review, vol. 30, pp. 314-325. 1970.

LOWI, Theodore J. Four Systems of Policy, Politics, and Choice. Public Administration Review, vol. 32, pp. 298-310. 1972.

MARQUES, Eduardo C. Notas críticas à literatura sobre Estado, políticas estatais e atores políticos. Revista Brasileira de Informação Bibliográfica em Ciências Sociais, v. 43, n. 1, p. 67-102, 1997.

MARSHALL, T. H. Cidadania, classe social e status. Rio de Janeiro. Zahar. 1967.

MINISTÉRIO DA EDUCAÇÃO. RESOLUÇÃO № 1, DE 13 DE JANEIRO DE 2014. Brasília, DF: Diário Oficial da União, $14 \quad$ jan. $2014 . \quad$ Disponível em: $<$ http://portal.mec.gov.br/index.php?option=com_docman\&view=download\&alias=14957-rces00114\&ltemid=30192>. Acesso em: 01 jul. 2019.

NAJBERG, Estela. Abordagens sobre o processo de implementação de políticas públicas. Interface, v. 3, n. 2, 2011.

NOGUEIRA, Marco Aurélio. As possibilidades da política: ideias para a reforma democrática do Estado. São Paulo: Paz e Terra, 1998.

NORTH, Douglass. Institutions, Institutional Change and Economic Performance. Cambridge: Cambridge University Press, 1990.

NUNES, Edson de Oliveira. Gramática política do Brasil: clientelismo e insulamento burocrático. Rio de Janeiro: Jorge Zahar, 1997.

OFFE, C. Problemas estruturais do Estado capitalista. Rio de Janeiro: Tempo Brasileiro, 1984. 
PIRES, R. R.; GOMIDE, A. D. Governança, Arranjos institucionais e capacidades estatais na implementação de políticas federais. Gestão e Políticas Públicas no cenário contemporâneo. Rio de Janeiro: Editora Fiocruz, 2016.

POULANTZAS, Nicos. O Estado, o poder e o socialismo. Rio de Janeiro. Edições Graal, 1980.

POULANTZAS, Nicos. Poder político y clases sociales en el Estado capitalista. Siglo XXI de España Editores, S.A., 2001.

PRESSMAN, Jeffrey; WILDAVSKY, Aaron. Implementation: how great hopes in Washington are dashed in Oakland. University of California Press, 1973.

PRZEWORSKI, Adam. Estado e economia no capitalismo. Tradução Argelina Cheibub Figueiredo, Pedro Paulo Zahluth Bastos. - Rio de Janeiro: Relume-Durnará, 1995.

SABATIER, Paul A. An advocacy coalition framework of policy change and the role of policy-oriented learning therein. Policy sciences, v. 21, n. 2-3, p. 129-168, 1988.

SABATIER, Paul A.; JENKINS-SMITH, Hank C. Policy change and learning: An advocacy coalition approach. Westview Press. 1993.

SALAMON, L. The Tools of Government: A Guide to the New Governance. New York: Oxford University Press. 2002.

SIMON, Herbert A. A behavioral model of rational choice. The quarterly journal of economics, v. 69, n. 1, p. 99-118, 1955.

SMITH, Adam. A riqueza das nações - investigação sobre sua natureza e suas causas. São Paulo. Abril Cultural, 1983.

SOUZA, Celina M. Federalismo e Políticas Públicas Nacionais: diversidade ou uniformidade? In: MENICUCCI, Telma Maria Gonçalves; GONTIJO, José Geraldo Leandro. Gestão e Políticas Públicas no Cenário Contemporâneo: tendências nacionais e internacionais. Rio de Janeiro: Editora Fiocruz, 2016.

TREVISAN, A. P.; VAN BELLEN, H. M. Avaliação de políticas públicas: uma revisão teórica de um campo em construção. Revista de Administração Pública, v. 42, n. 3, p. 529-550, 2008. 
WEBER, Max. A política como vocação. Brasília. EdUnB, 2003. 